\title{
Flavonoid Content and Antioxidant Properties in Different Extracts of Calluna vulgaris (L.) Flowers
}

\author{
Paulina Dróżdż ${ }^{1}$, Aleksandra Sentkowska ${ }^{2}$ and Krystyna Pyrzynska ${ }^{2}$ \\ 1. Laboratory of Environmental Chemistry, Forest Research Institute, 05-090 Raszyn, Sękocin Stary, Poland \\ 2. Department of Chemistry, University of Warsaw, Pasteura 1, 02-093 Warsaw, Poland
}

\begin{abstract}
This study evaluated the effect of four different solvent, i.e., water, ethanol, water-ethanol mixture and ethyl acetate, on the antioxidant activities of wild and cultivated heather (Calluna vulgaris (L.) Hull) plant. The highest values for total flavonoid content were obtained for samples extracted using ethanol-water mixture and ethyl acetate. Cupric reducing antioxidant capacity (CUPRAC) method, scavenging ability on 1,1-diphenyl-2-pirylhydrazyl radicals (DPPH) radicals and chelating activity on Fe ${ }^{2+}$ ions have been used for evaluation of antioxidant activity of the extracts. Ethanolic fraction exhibited the lowest reducing capacity, despite a heather sample used. The extracts of cultivated heather exhibited significant scavenging effect on DPPH radicals, and ethanol and ethanol-water fractions were found to be the most effective. The metal-chelating effect of the extracts increased in the order: ethanol $<$ ethyl acetate $<$ ethanol-water $<$ water. The results may be helpful for better utilization of heather flowers extracts as potential pharmaceutical and nutraceutical ingredient.
\end{abstract}

Key words: Calluna vulagaris (L.) Hull, heather, extraction, antioxidant activity.

\section{Introduction}

Flavonoids, benzo- $\gamma$-pyron derivatives with several hydroxyl groups attached to ring structures $\mathrm{C}_{6}-\mathrm{C}_{3}-\mathrm{C}_{6}$, are one of the most important groups of phenolic compounds occurring in plants. These compounds exhibit a wide range of biological effects, including antibacterial, anti-inflammatory, anti-allergic and anti-thrombotic actions [1]. These beneficial effects are mainly due to their antioxidant activity. Flavonoids can act as reducing agents, hydrogen donors, singlet oxygen quenchers, as well as a chelator of metal ions preventing metal catalyzed formation of free radicals [2].

In recent years, there is growing interest in evaluating the availability of natural plant extracts (with a pleasant smell and taste) as an alternative to the use of synthetic antioxidants, such as butylated hydroxyanisole (BHA) and butylated hydroxytoluene (BHT). The synthetic antioxidants seem to pose no

Corresponding author: Krystyna Pyrzynska, Ph.D., research fields: speciation analysis, functional foods, flavonoids in food samples, antioxidant properties. reasonable threat to health as at larger doses or long term ingestion may lead to chronic side effects [3, 4].

Heather (Calluna vulgaris (L.) Hull), a member of the Ericaceae family, can be found in most parts of Europe and Northern America. The plant material is a part of traditional folk medicine for treating urinary tract disturbances and inflammatory related disorders [5] as well as against the common cold and rheumatoid arthritis [6]. Pharmacological studies showed also antiseptic, antioxidant and monoamine oxidase A (MAO-A) inhibitory effects [7, 8].

The review of literature revealed very little data on antioxidant properties of different extracts of $C$. vulgaris flowers [8]. From various extraction studies, it was observed that the choice of solvent for extraction of flavonoids from plant materials was not coherent, which can be explained by the differences in the studied matrices as well as the complexity of flavonoids properties [9-11]. Thus, this research aimed to evaluate the effect of extraction solvent on the antioxidant activities of wild and greenhouse cultivated heather (C. vulgaris (L.) Hull) plants. The 
extracts from each plant were also evaluated for the determination of total flavonoid content, reducing power by cupric reducing antioxidant capacity (CUPRAC) method, scavenging ability on 1,1-diphenyl-2-pirylhydrazyl radicals (DPPH) radicals and chelating activity on $\mathrm{Fe}^{2+}$ ions. The results may be helpful for better utilization of heather flowers extracts as potential pharmaceutical and nutraceutical ingredient.

\section{Materials and Methods}

\subsection{Plant Material and Its Extraction}

The aerial parts of wild C. vulgaris were collected in Central Poland, Mazovia region, from 12-year-old pine wood $\left(52^{\circ} 41^{\prime} \mathrm{N}, 21^{\circ} 29^{\prime} \mathrm{E}\right)$. This sample was labelled as "wild heather". Sample of the cultivated garden $C$. vulgaris plant was obtained from the specialist garden store PNOS, Warszawa, Poland. Two popular cultivars were examined; the cultivar with violet flowers was labelled as garden-violet and with white flowers was labelled as garden-white. The collected plant materials were air dried at ambient temperature $\left(\sim 20^{\circ} \mathrm{C}\right)$ and stored in paper bags until performing analysis.

Dry plant materials $(700 \mathrm{mg})$ were mixed with 25 $\mathrm{mL}$ of solvent of pure water, ethanol, ethyl acetate and mixture of water-ethanol $(40: 60, \mathrm{v} / \mathrm{v})$, respectively, for $20 \mathrm{~min}$ at room temperature. Then, the extracts were filtered through Whatman No.1 filter paper. For a given sample, three independent extractions were carried out.

\subsection{Total Flavonoid Content}

The flavonoid content was determined according to two mostly applied spectrophotometric methods based on the formation of $\mathrm{Al}(\mathrm{III})-$ flavonoid complexes [12]. In first procedure, $0.5 \mathrm{~mL}$ of $2 \%(\mathrm{w} / \mathrm{v})$ of $\mathrm{AlCl}_{3}$ solution was mixed with $1 \mathrm{~mL}$ of sample and $0.8 \mathrm{~mL}$ of water. The mixture was vigorously shaken, and then after $10 \mathrm{~min}$ of incubation at room temperature, absorbance was measured at $430 \mathrm{~nm}$ using a
Perkin-Elmer model Lambda 20 spectrophotometer with cuvettes of $1 \mathrm{~cm}$ length. Quercetin (concentration range of $50-200 \mu \mathrm{M}$ ) was used as the reference compound.

In second procedure, $1 \mathrm{~mL}$ of sample was mixed with $0.3 \mathrm{~mL}$ of $\mathrm{NaNO}_{2}(5 \%, \mathrm{w} / \mathrm{v})$, and after $5 \min 0.5$ $\mathrm{mL}$ of $\mathrm{AlCl}_{3}(2 \%, \mathrm{w} / \mathrm{v})$ was added. A sample was mixed and 6 min later neutralized with $0.5 \mathrm{~mL}$ of $1 \mathrm{M}$ $\mathrm{NaOH}$ solution. The mixture was left for $10 \mathrm{~min}$ at room temperature and then subjected to spectral analysis. Catechin (in the $50-500 \mu \mathrm{M}$ concentration range) was the standard of choice for the expression of results at $510 \mathrm{~nm}$.

\subsection{Reducing Power}

The reducing power of the extracts of $C$. vulgaris was evaluated using CUPRAC method. $1 \mathrm{~mL}$ of 0.01 $\mathrm{M} \mathrm{CuCl}{ }_{2}$ solution was mixed with $1 \mathrm{~mL}$ of neocuproine solution $\left(7.5 \times 10^{-3} \mathrm{M}\right)$ and $1 \mathrm{~mL}$ of $1 \mathrm{M}$ acetate buffer, followed by addition $0.5 \mathrm{~mL}$ of extract and $0.6 \mathrm{~mL}$ of water. Then, a mixture was incubated in a water bath at a temperature of $50{ }^{\circ} \mathrm{C}$ for $20 \mathrm{~min}$, after which was cooled under running water. Absorbance against the reagent blank was measured at $450 \mathrm{~nm}$. The results were expressed as trolox equivalent ( $\mathrm{mM} / \mathrm{g}$ of dry matter). Analyses were run in three replicates.

\subsection{Scavenging Ability on DPPH Method}

Diluted sample extract $(0.1 \mathrm{~mL})$ was added to 2.4 $\mathrm{mL}$ DPPH solution $\left(3 \times 10^{-5} \mathrm{M}\right)$ in methanol. After 30 min, absorbance was measured at $539 \mathrm{~nm}$. Trolox solution in the concentration in range up to $1,000 \mu \mathrm{M}$ was used for the calibration curve and the results were expressed as trolox equivalent ( $\mathrm{mM} / \mathrm{g}$ of dry matter). Analyses were run in three replicates.

\section{$2.5 \mathrm{Fe}^{2+}$ Chelating Activity}

$1 \mathrm{~mL}$ of a given extract was mixed with $3.7 \mathrm{~mL}$ of distilled water. Then the mixture was reacted with 0.1 $\mathrm{mL} 2 \mathrm{mM} \quad \mathrm{FeCl}_{2}$ and $0.2 \mathrm{~mL}$ ferrozine. The 
absorbance was measured at $562 \mathrm{~nm}$. Chelating activities of the extracts (\%) were calculated in relation to the absorbance of the control sample. Analyses were run in three replicates and the results were averages.

\section{Results and Discussion}

Commonly used solvents for the extraction of flavonoids from plant material are ethanol or methanol, their mixtures with water, acetone and ethyl acetate [9, 13]. Several studies suggested that the content of flavonoids decreased with increasing concentration of alcohol above $60 \%(\mathrm{v} / \mathrm{v})[14,15]$. The presence of water is helpful to enhance swelling of plant material, which is favourable to increase the contact surface area between the plant matrix and the solvent, resulting in increase of the extraction yield [13].

Two methods for determination of total flavonoid content were evaluated for the extracts of heather flowers. First procedure was carried out in neutral medium, and after $\mathrm{AlCl}_{3}$ addition absorbance is measured at $430 \mathrm{~nm}$ with quercetin used as the standard compound for the expression of results. In the second procedure, complexation reaction was carried out in the presence of $\mathrm{NaNO}_{2}$ in alkaline medium, and absorbance was recorded at $510 \mathrm{~nm}$ with catechin as a standard compound. The absorption spectra of studied extracts applying the procedure 1

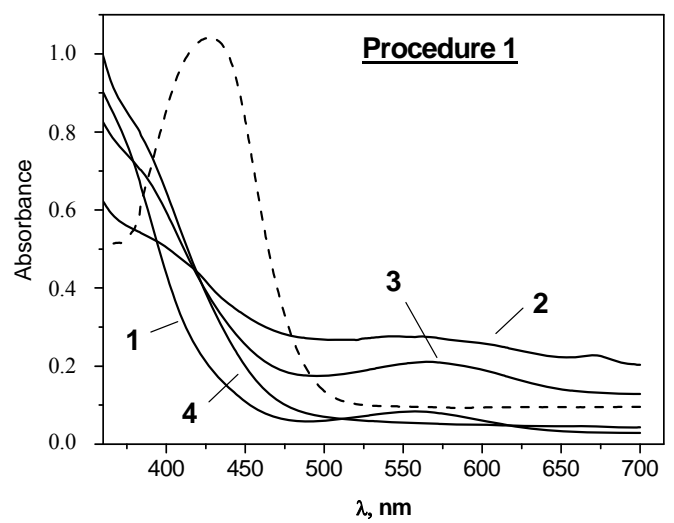

and procedure 2 are presented in Fig. 1, together with the spectra of the appropriate standard compounds. As could be seen, the studied extracts did not exhibite the absorbance peak characteristic for quercetin under the conditions used in procedure 1. Thus, quantification of total flavonoid content using this approach is misleading. In procedure 2 , the obtained spectra were similar to that of catechin. The extracts of C. vulgaris flowers are rich in catechins [16]. These compounds contribute mostly in total absorbance measured at 510 nm. Moreover, chlorogenic acid exhibited considerable absorbance at that wavelength, while the measurement is negligible under conditions in procedure 1 [12].

The results of total flavonoid contents, measured according to procedure 2, in tested extracts are presented in Table 1. The highest value was obtained for samples extracted using ethanol-water mixture and ethyl acetate. Isoflavones, flavanones, methylated flavones and flavonols are less polar flavonoids and are extracted with ethyl acetate $[9,13]$. Flavonoid glycosides and more polar aglycones are extracted with alcohols or alcohol water mixtures. Flavan-3-ols (catechins and condensed tannins) can often be extracted directly with water. Of the three heather samples, the extracts of garden-white cultivar had the highest total flavonoid content.

The reducing capacity of examined samples was

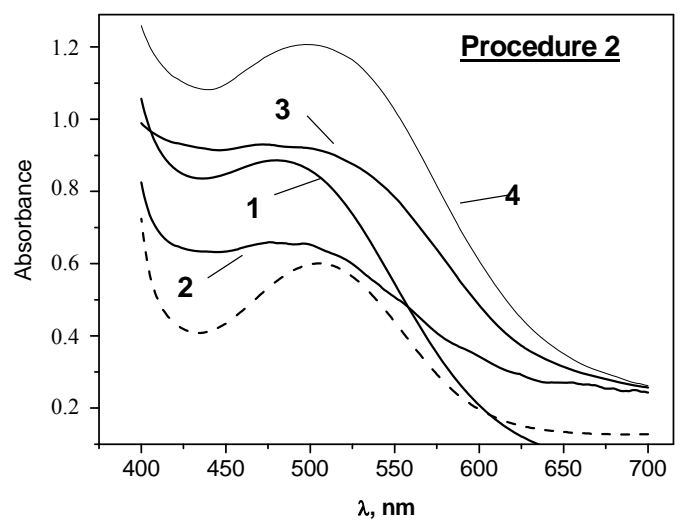

Fig. 1 The absorption spectra of heather flower extracts using water (1), ethanol (2), water-ethanol mixture (3) and ethyl acetate (4) after reaction with $\mathrm{AlCl}_{3}$ applying two procedures.

Dotted lines represent the spectra of the standard compounds quercetin and catechin, respectively, both at concentration of $0.10 \mathrm{mM}$, for procedure 1 and 2 . 
Table 1 The content of total flavonoids in C. vulgaris extracts by procedure 2.

\begin{tabular}{lllll}
\hline \multirow{2}{*}{ Samples } & \multicolumn{4}{c}{ Total flavonoids $(\mu \mathrm{M} / \mathrm{g})$ by different solvent } \\
\cline { 2 - 5 } & Water & Ethanol & Water-ethanol & Ethyl acetate \\
\hline Garden-violet & $96.1 \pm 3.1$ & $111.0 \pm 3.0$ & $130.0 \pm 3.5$ & $141.0 \pm 3.7$ \\
Garden-white & $92.7 \pm 1.4$ & $93.0 \pm 1.1$ & $182.0 \pm 3.1$ & $174.0 \pm 4.8$ \\
Wild & $74.6 \pm 2.9$ & $59.2 \pm 2.7$ & $145.0 \pm 4.5$ & $144.0 \pm 1.5$ \\
\hline
\end{tabular}

The results were expressed as $\mu \mathrm{M}$ of catechin/g of dry matter and represent mean \pm standard deviation $(n=3)$.

Table 2 Antioxidant activity of $C$. vulgaris extracts measured by different assays.

\begin{tabular}{llll}
\hline Samples & $\begin{array}{l}\text { CUPRAC } \\
\text { TE }(\mathrm{mM} / \mathrm{g})\end{array}$ & $\begin{array}{l}\text { DPPH } \\
\text { TE }(\mathrm{mM} / \mathrm{g})\end{array}$ & $\begin{array}{l}\text { Chelation } \\
(\%)\end{array}$ \\
\hline Water & & & $20.4 \pm 1.5$ \\
\hline Garden-violet & $9.1 \pm 0.4$ & $0.84 \pm 0.017$ & $30.3 \pm 2.9$ \\
Garden-white & $6.6 \pm 0.2$ & $0.47 \pm 0.013$ & $2.9 \pm 0.8$ \\
Wild & $6.6 \pm 0.4$ & $0.58 \pm 0.014$ & \\
\hline Ethanol & & & $6.6 \pm 0.3$ \\
\hline Garden-violet & $6.7 \pm 0.1$ & $1.43 \pm 0.078$ & $3.8 \pm 0.1$ \\
Garden-white & $6.0 \pm 0.3$ & $1.37 \pm 0.080$ & $5.2 \pm 0.4$ \\
Wild & $6.7 \pm 0.2$ & $0.87 \pm 0.040$ & $11.5 \pm 1.0$ \\
\hline Water-ethanol & & & $28.5 \pm 0.9$ \\
\hline Garden-violet & $10.9 \pm 0.8$ & $1.21 \pm 0.056$ & $5.7 \pm 0.3$ \\
Garden-white & $11.9 \pm 0.2$ & $1.37 \pm 0.049$ & $8.5 \pm 1.0$ \\
Wild & $11.1 \pm 0.5$ & $0.67 \pm 0.025$ & $25.1 \pm 0.9$ \\
\hline Ethyl acetate & & & $5.7 \pm 0.3$ \\
\hline Garden-violet & $12.2 \pm 0.5$ & $1.36 \pm 0.069$ & \\
Garden-white & $11.9 \pm 0.1$ & $0.71 \pm 0.029$ & $1.11 \pm 0.046$ \\
Wild & $10.0 \pm 0.3$ & &
\end{tabular}

Values represent mean \pm standard deviation $(n=3)$. TE: trolox equivalent.

evaluated by CUPRAC method base on the reduction of the $\mathrm{Cu}(\mathrm{II})$-neocuproine complex in neutral $\mathrm{pH}$ by reductants (antioxidants) present in a sample. The highest and similar results were obtained for the hydroalcoholic and ethyl acetate extracts. These extracts contained also the highest content of total flavonoids (Table 2). Ethanolic fraction exhibited the lowest content of reductants despite the investigated heather sample. It was reported that the ethyl acetate extract of aerial part of heather collected in northeastern part of Turkey gave the highest reducing properties (evaluated by Folin-Ciocalteau assay) followed by the $n$-butanol, chloroform and water [8].

Antioxidant capacity of the studied extracts was also assessed on the basis of their scavenging effect on the stable DPPH radical. That effect expressed as trolox equivalent is given in Table 2 . In the present study, ethanol and ethanol-water fractions were found to be the most effective in producing scavenging activity against DPPH radicals, and for garden-violet cultivar the highest values were obtained. Several studies showed also that cultivated plants possessed a higher free-radical scavenging activity against DPPH radicals than wild growing plant [17-19].

Polyphenols, in addition to reducing activities and free-radical scavenging, may have metal chelating activity that can inhibit the oxidative damage due to reactions catalyzed by the transition metals, such as Fe and $\mathrm{Cu}$. These oxidative reactions in vivo appear to be involved in the pathogenesis of at least some neurodegenerative diseases [20]. The metal-chelating effect of the extracts of heather flowers increased in the order: ethanol < ethyl acetate $<$ ethanol-water mixture $<$ water (Table 2). The high $\mathrm{Fe}^{2+}$ chelating 
activity was observed for greenhouse white cultivar. Water fractions can contain also tannins and proanthocyanins with high chelating affinity towards iron ions, which were previously found in this plant [21]. The chelating activities can not be mainly attributed to the total polyphenol or flavonoid contents but rather to specific compounds of the extract with a favourable chemical structure to metal complexation. It was demonstrated that the most effective iron binding site of flavonoids represents 6,7-dihydroxy structure [22]. The 3-hydroxy-4-keto conformation together with 2,3-double bond and the catecholic B ring were associated also with a substantial iron chelation.

\section{Conclusions}

The results of this research have provided an insight into the effect of the solvent used for the extraction of major flavonoids from the aerial parts of wild and greenhouse cultivated C. vulgaris (L.) Hull plant. Flavonoid contents and resulting antioxidant activities are strongly dependent on the nature of extracting solvent due to the presence of different antioxidant compounds of varied chemical characteristics and polarities. Ethyl acetate and ethanol-water mixture were proved to be the best solvent. The extracts of $C$. vulgaris may be considered a good source of the compounds with high antioxidant properties and may be explored in pharmaceuticals, foodstuffs, feed additives and cosmetics.

\section{Acknowledgments}

The authors would like to thank Forest Research Institute for financial support by the project No. 260801 "the possibility of utilization non-wood forest products (NWFPs) as a source of antioxidants in beneficial for health supplements".

\section{References}

[1] Del-Rio, D., Costa, L. G., Lean, M. E., and Crozier, A. 2010. "Polyphenols and Health: What Compounds Are Involved ?" Nutr. Metab. Cardiovasc. Dis. 20 (1): 1-6.
[2] Galleano, M., Verstraeten, S. V., Oteiza, P. I., and Fraga, C. G. 2010. "Antioxidant Actions of Flavonoids: Thermodynamic and Kinetic Analysis." Arch. Biochem. Biophys. 501 (1): 23-30.

[3] Trumbo, P. R. 2005. "Are There Adverse Effects of Lycopene Exposure?” J. Nutr. 135 (8): 2060-1.

[4] Trusheva, B., Trunkova, D., and Bankova, V. 2007. "Different Extraction Methods of Biologically Active Components from Propolis: A Preliminary Study." Chem. Centr. J. 1: 13.

[5] Monschein, M., Nira, J. I., Kunert, O., and Bucar, F. 2010. "Phytochemistry of Heather (Calluna vulgaris (L.) Hull) and Its Altitudinal Alteration." Phytochem. Rev. 9 (2): 205-15.

[6] Hooper, L., and Cassidy, A. 2006. "A Review of the Health Care Potential of Bioactive Compounds.” J. Sci. Food Agric. 86 (12): 1805-13.

[7] Saaby, L., Rasmussen, H. B., and Jäger, A. K. 2009. "MAO-A Inhibitory Activity of Quercetin from Calluna vulgaris (L.) Hull.” J. Ethnopharmacol. 121 (1): 178-81.

[8] Deliorman-Orhan, D., Şeno, S., Kartal, M., and Orhan, I. 2009. "Assessment of Antiradical Potential of Calluna vulgaris (L.) Hull and Its Major Flavonoid.” J. Sci. Food Agri. 89 (5): 809-14.

[9] Ajila, C. M., Brar, S. K., Verma, M., Tyagi, R. D., Godbout, S., and Valéro, J. R. 2011. "Extraction and Analysis of Polyphenols: Recent Trends." Crit. Rev. Biotechnol. 31 (3): 227-49.

[10] Kukula-Koch, W., Aligiannis, N., Halabalaki, M., Skaltsounis, A. L., Glowniak, K., and Kalpoutzakis, E. 2013. "Influence of Extraction Procedures on Phenolic Content and Antioxidant Activity of Cretan Barberry Herb." Food Chem. 138 (1): 406-13.

[11] Acosta-Estrada, B. A., Gutiérrez-Uribe, J. A., and Serna-Saldivar, S. O. 2014. "Bound Phenolics in Food: A Review." Food Chem. 152: 46-55.

[12] Pękal, A., and Pyrzynska, K. 2014. "Evaluation of Aluminium Complexation Reaction for Flavonoid Content Assay." Food Anal. Meth. 7 (9): 1776-82.

[13] Michiels, J. A., Kevers, C., Pincemai, J., Defraigne, J. O., and Dommes, J. 2012. "Extraction Conditions Can Greatly Influence Antioxidant Capacity Assays in Plant Food Matrices." Food Chem. 130 (4): 986-93.

[14] Wach, A., Pyrzynska, K., and Biesaga, M. 2007. "Quercetin Content in Some Food and Herbal Samples." Food Chem. 100 (2): 699-704.

[15] Waszkowiak, K., and Giszczyńska-Świgło, A. 2014. "Binary Ethanol-Water Solvents Affect Phenolic Profile and Antioxidant Capacity of Flaxseed Extracts." Eur. Food Res. Tech. 242 (5): 777-86.

[16] Dróżdż, P., Sentkowska, A., and Pyrzynska, K. 2016. "Biophenols and Antioxidant Activity in Wild and 
Cultivated Heather." Nat. Prod. Res. 31 (10): 1181-4.

[17] Conforti, F., Statti, G., Uzunov, D., and Menichini, F. 2006. "Comparative Chemical Composition and Antioxidant Activities of Wild and Cultivated Laurus nobilis L. Leaves and Foeniculum vulgare subsp. piperitum (Ucria) Coutinho Seeds.” Biol. Pharm. Bull. 29 (10): 2056-64.

[18] Lopez-Laredo, A. R., Gomez-Aguirre, Y. A., Medina-Perez, V., Salcedo-Morales, G., Sepúlveda-Jiménez, G., and Trejo-Tapia, G. 2012. "Variation in Antioxidant Properties and Phenolics Concentration in Different Organs of Wild Growing and Greenhouse Cultivated Castilleja tenuiflora Benth.." Acta Physiol. Plant 34 (6): 2435-42.

[19] Augusto, T. R., Scheuermann Salinas, E. S., Alencar, S. M., D'arce, B. R., Costa de Camargo, A. C., and Souza Vieira, T. H. M. 2014. "Phenolic Compounds and
Antioxidant Activity of Hydroalcoholic Extracts of Wild and Cultivated Murtilla (Ugni molinae Turcz.)." Food Sci. Tech. 34 (4): 667-73.

[20] Mandel, S., Amit, T., Reznichenko, L., Weinreb, O., and Youdim, M. B. 2006. "Green Tea Catechins as Brain-Permeable, Natural Iron Chelators-Antioxidants for the Treatment of Neurodegenerative Disorders." Mol. Nutr. Food Res. 50 (2): 229-34.

[21] Frutos, P., Hervas, G., Ramos, G., Giraldez, F. J., and Mantecón, A. R. 2002. "Condensed Tannin Content of Several Shrub Species from a Mountain Area in Northern Spain and Its Relationship to Various Indicators of Nutritive Value.” Anim. Feed Sci. Tech. 95 (3-4): 215-26.

[22] Mladenka, P., Macáková, K., Filipský, T., Zatloukalová, L., Jahodáŕ, L., Silvestri, I. P., Hrdina, R., and Saso, L. 2011. "In Vitro Analysis of Iron Chelating Activity of Flavonoids." J. Inor. Biochem. 105 (5): 693-701. 